\title{
Computerized monitoring of students' psychological profile
}

\author{
Nikolai Pavlov \\ Graduate School of Management and \\ Business \\ PeterThe Great St.Petersburg \\ Polytechnic University \\ St. Petersburg, Russia
}

\author{
Tatyana Nikonova \\ Karaganda State Technical University, \\ Karaganda, Kazakhstan
}

\begin{abstract}
This paper describes the usage of computerized procedure for monitoring students' propensity for entrepreneurship. The procedure is based on the method of choosing the best statements for psychological testing. A set of statements concerning entrepreneurial ability has been collected from various sources, and a procedure of test improvement based on Cronbach's alpha was performed for different categories of Russian and international students. Test statements that are the best for each category, shows the features that distinguish respondents of different entrepreneurial ability. Thus, the results gives characteristics that are important for different categories of native and foreign students. This procedure can be used to periodically adjust the curriculum of the future entrepreneurs and managers.
\end{abstract}

Keywords-entrepreneurship, psychological testing, propensity, Cronbach's alpha, monitoring

\section{INTRODUCTION}

Nowadays, almost all students spend a lot of time on the Internet. On the one hand, as the researchers, for example [1, 2], note, this leads to changes in the style of their thinking, perception, behavior and other features $[3,4]$. On the other hand, as they spend a lot of time on the Internet, it is possible to monitor changes in the students' psychological profiles on a regular basis by testing them via computerized surveys. Quite complex processing of the results is easily carried out with the help of modern statistical packages. Thus, in the digital age, it is possible to adapt the curriculum flexibly to a changing audience. This topic is developed in [5-7].

As an example of such a process, testing of such an important characteristic for economic specialties as entrepreneurial ability is considered.

This article describes the procedure of conducting such studies on the example of entrepreneurial ability. The research took place in 2017/2018 academic year among students of Peter the Great Polytechnic University. This research is important because in our university there are students not only from Russia, but also from different countries. In addition, some of our students are studying in joint groups. For them it is possible to get a double degree of Russian and foreign universities.

Such research allows to adjust the curriculum and make it better.

\section{THE METHOD OF RESEARCH}

\section{A. Approach}

Psychological characteristics are usually assessed by tests. The specifics of testing is that it is necessary to choose a set of questions that best reveal the studied characteristic. However, the set of "good" questions varies from one category of respondents to another, as well as from year to year. Therefore, an important role belongs to adjusting of tests. After "good" questions are selected, one can judge by which features the different respondents vary [8]

The method of developing tests based on Cronbach's alpha is described, for example, in $[9,10]$. Its essence lies in the development of a large number of statements on a specific topic, assigning a certain a priori weight to the answers (in the simplest case 0 - disagreement and 1 - agreement), and counting the total weight as the sum of weights of each answers. It is assumed that the majority of questions are "good", thus, the result obtained by the whole set of statements is considered true. The large value corresponds to a high level of the studied characteristics of the respondent. Then the test is improved. This is done by eliminating less useful questions. The quality of the test is evaluated through Cronbach's alpha. Zero value corresponds to a set of unrelated questions, and a value of $1-$ to the ideal test in which all questions have the same topic.

For evaluation of the quality of the test, Taber [11] collected different levels from the great number of sources and formulated the following scale that includes different opinions. If alpha is $0.93-0.94$, the test is excellent, $0.91-0.93$ - strong, 0.84-0.90 - reliable, 0.81 - robust, 0.76-0.95 - fairly high, $0.73-0.95$ - high, $0.71-0.91$ good, $0.70-0.77$ - relatively high, 0.68 - slightly low, $0.67-0.87$ - reasonable, $0.64-0.85-$ adequate, $0.61-0.65$ - moderate, $0.58-0.97$ - satisfactory, 0.45-0.98 - acceptable, 0.45-0.96 - sufficient, 0.4-0.55 - not satisfactory. These values helps to evaluate the quality of the obtained results.

The statistics package determines the alpha value for each question. It is the alpha value that the test will have if this question is deleted. Therefore, those questions, the removal of which improves the test, can be removed. Usually the result is a so-called domain - a set of questions, removing any question from which will only worsen the test.

Thus, the result is a set of questions that allows distinguishing respondents with varying degrees of the studied characteristic. 


\section{B. The Research Procedure}

Various sources were investigated to create the test of entrepreneurial ability. For example, in [12-16] the features of entrepreneurs are discussed theoretically, in [17] a test with text-based answers is given, and in [18] a test with Yes/No answers is presented. Summarizing the results of these and similar sources gave a test of 50 statements with Yes/No answers. The final set of statements is as follows.

I am ready to join in the solution of almost any problem.

I like to take risks.

I am willing to risk even for a small profit.

I am rarely satisfied and reassured.

I am patient.

I'm very active.

I'm strong enough to withstand stress.

I like competition very much.

I'm always looking for new ways of doing things.

I manage to find new ways to solve problems.

I'm calculating the consequences of my actions.

If necessary, I can make decisions quickly.

I take full responsibility for my actions.

I really like to achieve results.

I am happy to make many attempts to gradually solve a complex problem.

I overcome failure by choosing a different path and trying again.

I am ready to make sacrifices for the sake of achieving results in the distant future.

I am ready to bring the work to the end, despite the emerging obstacles.

I believe that even if my excellent work is not immediately rewarded, I will gain knowledge and experience from its implementation.

I like to use common sense.

I have intuition.

I learn from my mistakes.

I think even "old dogs can learn new tricks" and even come up with new ones.

I regularly interact with other people to get information and advice.

It is easy for me to communicate with people of different social status.

I understand other people's ideas and thoughts.

I can openly express my beliefs.

People are inspired by my ideas.

I can insist on my decision.

I like to organize people to do common work.
I think my colleagues respect me.

I do not like being pointed out by people more limited than myself.

I made money after school and during the holidays.

I really like being a seller.

I have already worked as a Manager or supervisor.

I like being an entrepreneur more than an employee.

I plan to start my own business.

I have some experience in the field in which I plan to start my business.

I have an innovative idea that I find useful.

My hobby is related to my business.

I can sacrifice a lot for my business.

I know quite well how business works.

I have knowledge in marketing and finance.

I understand the basics of balance sheet and accounting.

I can keep notes and notes regularly and accurately.

My friends have their own business.

My family members have their own business.

My family and friends will help me in my new business.

During the journey, I am willing to settle for a minimum of comfort.

I remain optimistic even in unpleasant situations.

The procedure of testing consisted of checking the statements with which the respondent agrees. The value of this answer is 1 . For disagreement the weight was 0 .

The processing of the results consists in counting the number of statements with which the respondent agrees. The more the result - the higher the level of entrepreneurial ability.

An electronic test was made with the help of webanketa.com and the link to this questionnaire was distributed among third year bachelor and first year master students of the Graduate School of Management and Business of Peter the Great St. Petersburg Polytechnic University.

There are several ways to perform such surveys.

Recently, each student of our University has a personal account on the university site, where a link to this questionnaire can be placed.

In addition, students often create a social media account for their groups. This is also a useful place for a link to this test. It would be useful to create such an account for every group on the university site.

For the first time the questionnaire was filled out by students at the practical classes of Marketing Research and International Market Research. The lesson was devoted to the testing of psychological attributes. However, this last method is only suitable for the groups in which such courses are taught. 
The test results were processed using Statistica package, the licensed version of which is used in the statistics course. The SPSS package has similar capabilities.

The respondents - 200 bachelor and master students were divided into the following categories, according to the hypothesis of a possible difference in their profiles:

- Russian students in regular groups. They form the majority in the University - 84 people;

- Russian students in international groups. Many Russian students are obtaining a double degree and study in international groups. Many courses are in English. Perhaps, their views about entrepreneurship differ from other groups -25 people;

- Foreign students from China. Students from this country are the majority of foreign students in our University. They are representatives of the Eastern civilization, perhaps, their features differ from other groups) - 17 people;

- Other international students. The University has many students from different countries. But they all came to our country, often - from the other side of the globe. It is assumed that this they form a special group. In this research it is not possible to study students from each country separately as in this case the number of students from some countries is too small. This may be the next stage of research -74 people.

\section{OBTAINED RESULTS}

\section{A. Description of categories}

1) Russian students

$\alpha$ for all questions is equal to .86; $\alpha$ for improved test (domain) is equal to .88. Five most important characteristics with determination coefficient in brackets are as follows:

I would rather prefer to become an entrepreneur than a hired worker (.39);

I am able to insist on solution made (.26);

I have the emotional strength to withstand stress (.25);

I am innovative in finding solutions to problems and challenges $(.25)$;

I plan to start my own business (.24).

2) Russian students in international groups

$\alpha$ for all questions is equal to .58; $\alpha$ for improved test (domain) is equal to .81. Five most important characteristics with determination coefficient in brackets are as follows:

My family and friends will be supportive of my new venture (.33);

I am highly active (.33);

I regularly network with others to gain information and guidance (.29);

I always look for new ways to do things (.24);

I am willing to make sacrifices for possibly gaining lasting rewards (.24);

\section{3) Chinese students}

$\alpha$ for all questions is equal to $.82 ; \alpha$ for improved test (domain) is equal to .88. Five most important characteristics with determination coefficient in brackets are as follows:ол

I worked after school and during vacations when I was growing up (.61);

I plan to start my own business (.46);

I can express my opinion openly (.37); (.36);

Whenever there is a problem, I am ready to jump right in

My hobby is related with my business (.30).

4) Other international students

$\alpha$ for all questions is equal to .74; $\alpha$ for improved test (domain) is equal to .81 . Five most important characteristics with determination coefficient in brackets are as follows:

I have some experience in the area that I have chosen to start my business in (.27);

I am willing to take risky chances (.26);

I have friends who run their own businesses (.24);

People get excited by my ideas (.23);

I have sound financial knowledge of how a business operates (.17)

\section{B. Findings}

Cronbach's alpha for the initial version of the test varies from .58 to .74 , which indicates that the answers are definitely not random.

The greatest improvement of the test after removal of unsuccessful questions is observed among Russians in foreign groups, which indicates the diversity of their psychological portraits.

Among the group of foreign students, the coefficient of determination does not exceed .27. This is the smallest value among different groups. Obviously, this is because they are students from very different countries.

Among Chinese students, one question has a very high coefficient of determination equal to .61 .

So, one can see what features determine the propensity to entrepreneurship among different groups of students. All groups appeared to be different.

Most of the features that comprise entrepreneurial ability are personal. Nevertheless, several features are not directly related to the personality:

- help of family and friends for Russians in foreign groups;

- $\quad$ practical experience for Chinese students;

- previous experience, business knowledge and finance for international students.

\section{Possible usage of results}

When teaching different groups of students one should pay attention to their propensity. For the training of entrepreneurs, it is advisable to develop the marked personal features. 
As the first improvements in the teaching of managementrelated courses, it is advisable to move away from the tasks, which are the same for everyone, differing only in the values of initial data. Instead, it would be more useful to set up a Bank of case studies with different emphasis within the general course program.

For Russian students, tasks should focus on the development of startups, as well as on the inventing and justification of management decisions.

For Russian students studying in foreign groups, the emphasis is on finding solutions in the group, as well as justification of the costs of implementing these solutions.

For Chinese students, it is advisable to give tasks based on the organizations that are familiar to them.

Finally, international students from other countries, most of whom already have basic knowledge, will appreciate the tasks of generating, substantiating and presenting new ideas.

The author already uses the approach of creating workbooks containing a variety of tasks, the number of which significantly exceeds the number of practical exercises. This allows flexibly selecting the jobs that are most suitable for different students according to their interests.

\section{DISCUSSION}

In some groups, the number of respondents is rather small, so the results may not be entirely accurate. It is proposed to conduct regular monitoring. For the same reason, only a small number of important features are considered in this paper. When removing less useful questions, there could be minor errors in calculations of alpha, so there is no guarantee that the questions were removed in order of their actual uselessness. However, the most important questions are determined with high reliability.

The results may change from year to year, but this is the next stage of research.

Similar studies can be carried out for other psychological characteristics, for example, the leadership ability, propensity for research work.

Thus, a procedure is proposed for monitoring the features by which certain qualities of future economists and managers are determined in order to adapt the process of their training.

This paper was financially supported by the Ministry of Education and Science of the Russian Federation on the program to improve the competitiveness of Peter the Great St. Petersburg Polytechnic University (SPbPU) among the world's leading research and education centers in the 20162020 .

\section{REFERENCES}

[1] Feifer J. "The Next Generation of Entrepreneurs Are Amazing. Let's Support Them!”. - 2018. https://www.entrepreneur.com/article/317647.

[2] Carreau D. "Gen Z Brings a Whole New Dynamic to the Workforce". - 2018. - https://www.entrepreneur.com/article/322584

[3] Kankovskaya, A., Kalinina, O., Ilin, I. Economics of transport and sustainable development: Problems of high education in Russia (2018) MATEC Web of Conferences, 239, № 08008 .

[4] Zhukov, D., Khvatova, T., Lesko, S., Zaltcman, A. "Managing socia networks: Applying the percolation theory methodology to understand individuals' attitudes and moods", in Technological Forecasting and Social Change, 129, - 2018. - pp. 297-307.

[5] Bagaeva, I., Iliashenko, O., Borremans, A. "Theoretical and methodological aspects of the competence approach to the evaluation of the organization's personnel", in MATEC Web of Conferences, 193. -2018 .

[6] Iljashenko, O., Bagaeva, I., Levina, A. Strategy for establishment of personnel KPI at health care organization digital transformation (2019) IOP Conference Series: Materials Science and Engineering, 497 (1), № 012029

[7] Kharlamova, T. "Monitoring as an instrument of Sustainable Urban Development" in MATEC Web of Conferences, 170, - 2018. - article № 02009 .

[8] McDaniel C., Jr., Gates R. "Markeing Research”. Wiley. - 2018. - 324

[9] Kaplan R.M. "Psychological Testing: Principles, Applications, and Issues". Cengage Learning US. - 2017. - 512 p.

[10] Ilin, I.V., Iliashenko, O.Y., Klimin, A.I., Makov, K.M. Big data processing in Russian transport industry (2018) Proceedings of the 31st International Business Information Management Association Conference, IBIMA 2018: Innovation Management and Education Excellence through Vision 2020, pp. 1967-1971.

[11] Taber K.S. "The Use of Cronbach's Alpha When Developing and Reporting Research Instruments" in Science Education Research in Science Education, December 2018, Volume 48, Issue 6, pp 12731296.

[12] Elizabeth R., Kitchen C. "Personality Traits of a Successful Entrepreneur". https://www.brighthub.com/office/entrepreneurs/articles/60188.aspx.

[13] Klochkov, Y. S., Lepehin, A. I., Vasilega, D. S., Vasilega, N. A., Nonieva, K. Z., \& Vasilyeva, S. E. (2018). Professional orientation of students. Paper presented at the Proceedings of 2017 IEEE 6th Forum Strategic Partnership of Universities and Enterprises of Hi-Tech Branches (Science. Education. Innovations), SPUE 2017, 2018January, 165-167.

[14] Rasskazova, O., Kalinina, O., Zotova, E. Modern transformation of the production structure and its impact on the content of labor and the requirements for the skills and abilities of workers (2018) 170, 01041.

[15] Bril, A., Kalinina, O., Zotova, E., Vilken, V. Increasing the efficiency of personnel management in municipal organizations through controlling operational risks and fixed costs (2018) 170, 01040.

[16] Ngah R., Salleh Z. "Emotional Intelligence and Entrepreneurs' innovativeness towards Entrepreneurial Success: A Preliminary Study", in American Journal of Economics 5(2). - 2015. - pp. 285-290.

[17] "The Entrepreneur Test | Am I Entrepreneur? Entrepreneurship". Quiz. https://www.bizmove.com/other/quiz.htm

[18] Myler L. "Want To Be An Entrepreneur? Take This Test To See If You're Ready". - 2012 https://www.forbes.com/sites/larrymyler/2012/09/19/want-to-be-anentrepreneur-take-this-test-to-see-if-youre-ready/\#315c07464f7a9. 